\title{
Image case: Extraction of Large Stone from the Common Bile Duct
}

\author{
Tarik I Zaher \\ Tropical Medicine Department, Faculty of Medicine, Zagazig University, Egypt
}

Corresponding author: Tarik I Zaher

email:

tareqzaher@zu.edu.eg

mobile:

$+201001855393$

Received :26/4/2012

Accepted after

revision: $28 / 5 / 2012$
A 60 years old women presented by abdominal pain and recurrent bouts of fever 4 years after cholecystectomy. Abdominal ultrasonography revealed dilated common bile duct and stone inside. Serum bilirubin was mildly elevated.

The definition of a large stone should include the lower CBD diameter so that any stone exceeding that should be called "large", regardless of the stone size[1]. Biliary plastic stents plus endoscopic sphincterotomy without stone extraction as primary therapy at initial ERCP is a safe and effective method in the management of large or multiple CBD stones .Hong et al found that the total stone clearance at second ERCP after stenting was $94.2 \%$, only $5.7 \%$ of which needed mechanical lithotripsy [2]. Endoscopic sphincterotomy plus large-balloon dilatation (ESLBD) after endoscopic sphincterotomy is a simple, reproducible and effective technique, associated with a low morbidity rate and
Endoscopic retrograde cholangiopancreatography (ERCP) revealed dilated common bile duct with large stone inside. Sphincterotomy was done and large stone was extracted by basket forceps.

helps in avoiding mechanical lithotripsy in $95.3 \%$ of cases for the endoscopic extraction of large or multiple common bile duct stones [3].

So the great majority of patients with large stones can be treated endoscopically. In cases of unsuccessful stone extraction using balloons, baskets, mechanical lithotripsy, electrohydraulic or laser lithotripsy and large balloon dilation, the patient should be referred for extracorporeal shock wave lithotripsy or a percutaneous approach and finally surgery[1] . 


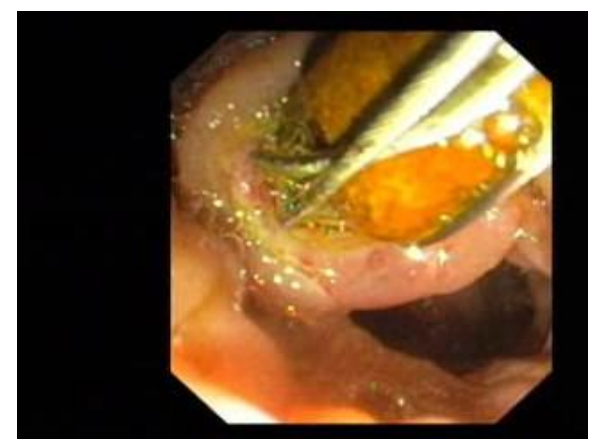

Image (1): Large stone during extraction by basket forceps outside the common bile duct.

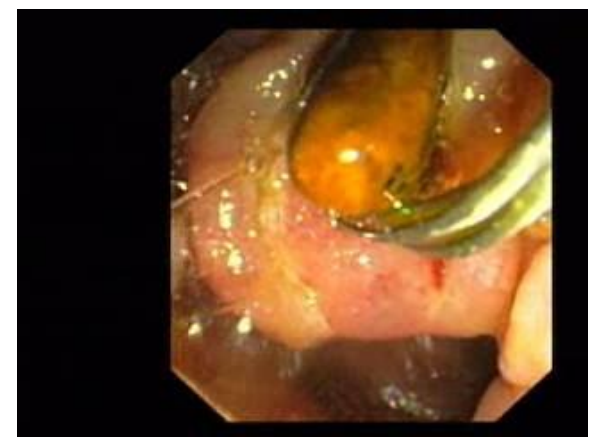

Image (2): Another view of the stone.

\section{REFERENCES}

1. Stefanidis G, Christodoulou C, Manolakopoulos S, Chuttani R. Endoscopic extraction of large common bile duct stones: A review article. World J Gastrointest Endosc 2012 May 16;4(5):167-79.

2. Hong WD, Zhu QH, Huang QK.. Endoscopic sphincterotomy plus endoprostheses in the treatment of large or multiple common bile duct stones. Dig Endosc 2011 Jul;23(3):240-3.
3. Poincloux L, Rouquette O, Privat J, Gorce D, Abergel A, Dapoigny M, Bommelaer G.Largeballoon dilation of the sphincter of Oddi after sphincterotomy or infundibulotomy to extract large calculi or multiple common bile duct stones without using mechanical lithotripsy. Scand J Gastroenterol 2012 Jan 10. [Epub ahead of print]. 